\title{
Estimation of Intracranial Pressure by Ultrasound of the Optic Nerve Sheath in an Animal Model of Intracranial Hypertension
}

\author{
Brasil Chian Jeng \\ Univerisity of São Paulo \\ Almir Ferreira de Andrade \\ Universty of São Paulo
}

Sérgio Brasil ( $\sim$ sbrasil@alumni.usp.br)

University of São Paulo https://orcid.org/0000-0003-2397-9947

Edson Bor-Seng-Shu

University of São Paulo

Alessandro Rodrigo Belon

University of São Paulo

Maira Robertis

University of São Paulo

Marcelo de-Lima-Oliveira

University of Sao Paulo: Universidade de Sao Paulo

Andrés Mariano Rubiano

Universidad El Bosque

Daniel Agustín Godoy

Sanatorio Pasteur

Manoel Jacobsen Teixeira

University of São Paulo

Wellingson Silva Paiva

University of Sao Paulo

\section{Research}

Keywords: optic nerve sheath diameter, ultrasonography, brain injury, intracranial hypertension, animal model

Posted Date: December 16th, 2020

DOI: https://doi.org/10.21203/rs.3.rs-127676/v1

License: @ (i) This work is licensed under a Creative Commons Attribution 4.0 International License. Read Full License 


\section{Abstract}

Background: Invasive monitoring of intracranial pressure (ICP) is currently the gold standard method for the safe diagnosis and treatment of intracranial hypertension (ICHy), but it is subject to hemorrhage, infection and malfunction. Ultrasound of the optic nerve sheath diameter (ONSD) has been applied as a non-invasive alternative that is cost effective and available at the bedside. However, ONSD time-lapse behavior in a set of ICHy and its relief by means of whether saline infusion or surgery is still unknown. The objective of this study was to correlate intracranial pressure and ultrasonography of the optic nerve sheath in an experimental animal model of ICHy, and the interval needed to ONSD to return to its baseline levels.

Methods: An experimental study was conducted on 30 male and female pigs weighing about $20 \mathrm{~kg}$. The diameter of the optic nerve sheath was evaluated by ultrasound at different measures of ICP given by intraventricular catheter and intracranial balloon inflation, saline infusion and balloon deflation. Laboratory and hemodynamic data were collected from the animals. ICP and ONSD values were correlated at each time point of the study.

Results: All the variables obtained by ONSD ultrasonography as left optic nerve, right optic nerve and average of optic nerve sheath (AON) diameter were statistically significant to estimate ICP value. ONSD values changed immediately at balloon inflation, with a delay of 30 minutes average to return to baseline levels after balloon deflation $(p=0.016)$. No statistical significance was observed in ICP and ONSD values with hypertonic saline infusion. Correlation between ICP and ONSD was linear and can be estimated using the formula: $-80.5+238.2 x$ AON, in this swine model.

Conclusion: In the present study, ultrasound of optic nerve sheath diameter disclosed linear correlation with ICP, although a short delay in returning to its baseline levels may be observed in the case of sudden intracranial hypertension relief.

\section{Background}

Invasive monitoring of intracranial pressure (ICP) is the gold standard technique for the safe diagnosis of ICP increase and the treatment of intracranial hypertension (ICHy) (1,2), with especial recommendation for Intraventricular catheters and cerebrospinal fluid drainage if needed (3).

Although there are clear benefits of the continuous and real-time monitoring provided by invasive methods, the risk of complications limits its use, such as bleeding (1.1-5.8\%), catheter malfunction (6.3-40\%) and infection $(0-15 \%)$ with risk of bacterial catheter colonization after the fifth day (3-7).

When compared to computed tomography and nuclear magnetic resonance imaging, optic nerve sheath diameter (ONSD) ultrasound has many advantages. It is available at the bedside, is easily repeatable and eliminates the need for transporting critical patients. However, there are currently few techniques to estimate ICP without surgical procedures, mainly transcranial Doppler based $(8,9)$. Compared to TCD, ONSD ultrasound is easier to apply and has a smaller learning curve (10). The determination of a correlation between the values obtained by ONSD ultrasound with ICP may overcome this limitation.

ONSD has already demonstrated moderate correlation with ICP $(8,11-14)$, although issues about time-lapse on decreasing its values in case of ICP reduction still remain. Therefore, the aim of this study was to verify the 
correlation in an experimental animal model of controlled ICP elevation by means of balloon inflation and interventions to ICP reduction, observing ONSD values and propose a method for ICP estimation.

\section{Methods}

\section{Study subjects}

We studied 30 piglets hybrids of the Landrace, Duroc, and Pietrain breeds. The selected animals were about 60 days of age, weighing between 18 and $22 \mathrm{~kg}$, and with hemoglobin levels between 8.5 and $12.0 \mathrm{~g} / \mathrm{dL}$.

They were anaesthetized with propofol $5-10 \mathrm{mg} / \mathrm{kg} / \mathrm{h}$ ( $1 \%$ Provine $\left.{ }^{\circledR}\right)$, and fentanyl was used for analgesia (Fentanest ${ }^{\circledR}$, Cristália) at an initial dose of $5 \mu \mathrm{g} / \mathrm{kg}$ followed by a continuous infusion of $0.08-0.15 \mathrm{mg} / \mathrm{kg} / \mathrm{min}$. The animals were intubated and mechanically ventilated at a controlled volume (Fan Dixtal ${ }^{\circledR} 5010$ ), with a tidal volume of $10 \mathrm{ml} / \mathrm{kg}$ and a fraction of inspired oxygen of 0.40 . The invasive monitoring of the mean arterial blood pressure (MABP) was performed using a right femoral artery catheter. End tidal $\mathrm{CO}_{2}\left(\mathrm{ETCO}_{2}\right)$, peripheral hemoglobin saturation $\left(\mathrm{SpO}_{2}\right)$, and systemic $\mathrm{pH}$ were continuously monitored.

Two 3-mm holes were made $1 \mathrm{~cm}$ lateral to the metopic suture: one for a multiparameter cerebral catheter to measure intracranial pressure, temperature, and tissue oxygen (microsensor-type microchip, Neurovent-PTiO ${ }^{\circ}$; Raumedic), which was placed in a hole anterior to the coronal suture and inserted $1.5 \mathrm{~cm}$ deep into the frontal lobe, and the other for a pediatric 8-French bladder catheter, which was placed in a hole $1 \mathrm{~cm}$ posterior to the coronal suture and inserted $2 \mathrm{~cm}$ deep into the parietal lobe. In this nontraumatic model, after each animal was prepared, the pediatric catheter balloon was progressively inflated with $0.9 \%$ saline solution over 15 min using continuous pump infusion until $4 \mathrm{ml}$ or $7 \mathrm{ml}$ was infused.

A LOGIQ Book XP portable ultrasound system (GE Healthcare, Milwaukee, WI) was used for this study, and a high frequency transducer of $10 \mathrm{MHz}$ linear array. The images were digitally acquired and stored on the system's hard drive. The same probe was used throughout the experiment. Ultrasound was performed on both eyes of each animal by an operator blinded to the ICP and balloon volume (Fig. 1). The image plane was chosen to achieve the best longitudinal image of the optic nerve for cross-sectional diameter measurements.

Figure 1

\section{Study flow}

The experiment included three randomized groups according to the volume inflated into the balloon: $4 \mathrm{~mL}, 4 \mathrm{~mL}+$ $3 \mathrm{~mL}$, and $7 \mathrm{~mL}$. Each group consisted of 10 animals that underwent saline $(3 \% \mathrm{NaCl})$ solution infusion, and balloon deflation.

In the $4 \mathrm{~mL}$ group, an intracranial hematoma was simulated with a volume of $4 \mathrm{~mL}$. This would be equivalent to the collection of approximately $80 \mathrm{ml}$ in an adult human, taking into account the ratio between the animal's brain weight at 2 months with a body weight of $18 \mathrm{~kg}$ (mean of $75 \mathrm{~g}$ ) and a normal adult brain weight $(1500 \mathrm{~g}$ ) (with a body weight/body weight ratio of 5\%). The hypertonic saline solution was infused 1 hour after the end of the inflation of the balloon. One hour after the end of the infusion of hypertonic saline solution, a final intervention was performed, the balloon was deflated, simulating a surgical procedure. In the $7 \mathrm{~mL}$ group, a volume of $7 \mathrm{ml}$ was used, equivalent to a volume of approximately $140 \mathrm{ml}$ in an adult human. In the $4 \mathrm{~mL}+3 \mathrm{~mL}$ group 30 
minutes after the initial volume of $4 \mathrm{ml}$, we added $3 \mathrm{ml}$, simulating expansion and generating an end volume of $7 \mathrm{ml}$.

Diameters of the left and right optic nerve sheaths were measured 3 times at 9 timepoints after the beginning of the experiment: basal, balloon 1st (immediately after the first inflation of the balloon), balloon 2nd (immediately after the second balloon inflation or 30 minutes after balloon 1st ), pre-saline, saline (immediately after infusion of saline), post-saline, pre-intervention, intervention (immediately after balloon deflation), and post-intervention (30 and 60 minutes after balloon deflation). The average value of these three measures (LON, RON) was used for statistical analysis; the average optic nerve sheath value (AON) was calculated from the mean LON and RON $(\mathrm{LON}+\mathrm{RON} / 2)$. Table 1 shows the volume inflated into the balloons at each time point.

Table 1

Diameters of the left and right optic nerve sheaths were measured at 9 timepoints after the beginning of the experiment: basal, balloon 1 (immediately after the first inflation of the balloon), balloon 2 (immediately after the second balloon inflation or 30 minutes after balloon 1), pre-saline, saline (immediately after infusion of saline), post-saline, pre-intervention, intervention (immediately after balloon deflation), and post-intervention. The volume $(\mathrm{mL})$ inflated in the balloon in each group at each timepoint is shown above.

\begin{tabular}{|llllllllll|}
\hline & basal & $\begin{array}{l}\text { balloon } \\
1\end{array}$ & $\begin{array}{l}\text { balloon } \\
2\end{array}$ & $\begin{array}{l}\text { pre } \\
\text { saline }\end{array}$ & saline & $\begin{array}{l}\text { post } \\
\text { saline }\end{array}$ & $\begin{array}{l}\text { pre } \\
\text { intervention }\end{array}$ & intervention & $\begin{array}{l}\text { post } \\
\text { intervention }\end{array}$ \\
\hline $4 \mathrm{~mL}$ & 0 & 4 & 4 & 4 & 4 & 4 & 4 & 0 & 0 \\
\hline $\begin{array}{l}4 \mathrm{~mL} \\
+ \\
3 \mathrm{~mL}\end{array}$ & 0 & 4 & 7 & 7 & 7 & 7 & 7 & 0 & 0 \\
\hline $7 \mathrm{~mL}$ & 0 & 7 & 7 & 7 & 7 & 7 & 7 & 0 & 0 \\
\hline
\end{tabular}

Table 1

After the end of the experiment and data collection, the animals received an anesthetic overdose of propofol and fentanyl, sacrificed with intravenous administration of $20 \mathrm{ml}$ of $19.1 \%$ potassium chloride solution. The protocol was approved by the Research Ethical Committee at São Paulo University Medical School.

\section{Statistical analysis}

The animal's weights were described according to groups using means and standard deviations and compared the groups using analysis of variances (Neter, et. Al., 1996), the sexes of the pigs were described according to groups and verified the association with the use of the likelihood ratio test (Kirkwood and Sterne, 2006).

The evaluated parameters were described according to groups and moments of evaluation using summary measures (mean, standard deviation, median, minimum and maximum) and compared between groups and moments using generalized estimation equations with normal marginal distribution and function of identity link (McCullagh and Nelder, 1989) with interchangeable correlation matrix between the moments of evaluation. Only for PtiO2 marginal range distribution was used, due to the asymmetric distribution of values. The analyzes were followed by Bonferroni's multiple comparisons (Neter, et. Al., 1996) to verify where the differences between groups and moments of evaluation occurred when significant.

ICP values were estimated according to the left and right optic nerve sheath and mean of both using generalized estimation equations with normal distribution and identity link function with interchangeable correlation matrix 
between the moments of evaluation.

The results were illustrated using graphs of average profiles with the respective standard errors. The analyzes were performed using the IBM-SPSS for Windows version 20.0 software and tabulated using the Microsoft-Excel 2003 software and the tests were performed with a $5 \%$ significance level.

Data on intraparenchymal ICP and brain temperature were obtained and stored at 1-minute intervals by the monitor (MPR2 logO Raumedic $®$, Munchberg, Germany). The values of the optic nerve sheath were recorded in the ultrasound system and in a spreadsheet program (Microsoft Excel 2007, Microsoft Corp., Redmond, United States). Statistics software (SPSS 20.0; SPSS, Inc., Chicago, United States) was used to generate the linear correlation curve between the studied parameters.

\section{Results}

All animals were hemodynamically stable during the experimental procedure (physiological variables such as $\mathrm{MABP}$, temperature, $\mathrm{ETCO}_{2}, \mathrm{SaO}_{2}$ were regular during the experiments). The mean ICP values of the three groups differed statistically throughout the studied timepoints. Despite similar final volumes of insufflation $(7 \mathrm{~mL})$, the $4 \mathrm{~mL}+3 \mathrm{~mL}$ and $7 \mathrm{~mL}$ groups presented different mean ICP values. The $4 \mathrm{~mL}+3 \mathrm{~mL}$ group presented higher mean ICP values at the balloon 2 nd timepoint, when it reached $7 \mathrm{~mL}$ of insufflation.

In the $4 \mathrm{~mL}$ group, mean ICP values did not exceed $17 \mathrm{mmHg}$, which leads us to conclude that $4 \mathrm{~mL}$ was insufficient to generate ICHy in the studied animals. In the $4 \mathrm{~mL}+3 \mathrm{~mL}$ group, the mean ICP values showed a significant increase in relation to the baseline of the first inflation until the time of the intervention, not statistically returning to baseline levels immediately, but 30 minutes later. Hypertonic saline solution did not significantly influence the ICP, unlike emptying the balloon (Fig. 2).

\section{Figure 2}

In the $7 \mathrm{~mL}$ group, ICP was elevated in relation to baseline after the influx of $7 \mathrm{~mL}$ at the balloon $1 \mathrm{st}$ timepoint and was maintained until the moment of pre intervention. From the moment of injection, the ICP returned to the baseline value until the end of the experiment. Again, hypertonic saline solution did not significantly influence ICP, unlike balloon deflation, which was the only method that controlled the ICHy obtained in the both groups, reducing the ICP values to the levels observed at baseline.

The variation in the mean diameter of the optic nerve sheaths was statistically different between the 3 groups ( $4 \mathrm{ml}$ flask, $4+3 \mathrm{ml}$ flask and $7 \mathrm{ml}$ flask over the different moments of the experiments $(\mathrm{p}=0.021)$. The mean diameter of the optic nerve sheath showed the highest values in the $4 \mathrm{~mL}+3 \mathrm{~mL}$ group, and the $4 \mathrm{~mL}$ group presented the smallest measurements of the optic nerve sheath at all times.

At balloon 1st, when inflating $4 \mathrm{~mL}$, we did not observe a significant increase in the ONSD similar to that observed with the ICP. AON presentation changes in relation to baseline from the moment of balloon inflation $(p=0.007)$. In the moment after deflation of the balloon, we observed a significant reduction in AON in relation to the other moments of the experiment ( $p=0.007)$. The ICP also showed statistically significant differences between the same moments. AON presented a variation similar to the ICP measurements in the 2 groups in which it was possible to generate intracranial hypertension $(4 \mathrm{~mL}+3 \mathrm{~mL}$ and $7 \mathrm{~mL}$ ) presenting sustained elevation at the moments when the balloon was inflated. For all groups AON had returned to baseline levels at the second 
evaluation (30 minutes) after ICP returning for baseline levels (Fig. 3), maintaining values higher than baseline immediately after the balloon deflation moment $(p=0.016)$.

Figure 3

All the variables obtained by ONSD ultrasonography (LON, RON and AON) were statistically significant to predict the ICP value (Fig. 3). AON proved to be the best parameter for predicting ICP and presented the best correlation. Thus, ICP can be estimated using the linear function: ICP = $(238.2 \times \mathrm{AON}) \mathbf{- 8 0 . 5}$ (Table 2).

Table 2

LON, RON and AON were statistically significant to estimate ICP value. However, the best fit criterion of the models showed a lower value for the model with AON, ICP was estimated by means of linear function. FD: freedom degrees, CQLC: corrected quasi-likelihood coefficient.

\begin{tabular}{|c|c|c|c|c|c|c|c|}
\hline \multirow[t]{2}{*}{ Factor } & \multirow[t]{2}{*}{ Coeficient } & \multirow[t]{2}{*}{ Standard error } & & \multirow[t]{2}{*}{ Statistic test (Wald) } & \multirow[t]{2}{*}{ FD } & \multirow[t]{2}{*}{$\mathrm{p}$} & \multirow[t]{2}{*}{ CQLC } \\
\hline & & & Upper & & & & \\
\hline Intercept & $-79,8$ & 11,7 & $-56,92$ & 46,66 & 1 & $<0,001$ & \multirow[t]{2}{*}{88402} \\
\hline LON & 239,0 & 26,7 & 291,47 & 79,87 & 1 & $<0,001$ & \\
\hline Intercept & $-63,5$ & 10,9 & $-42,18$ & 34,19 & 1 & $<0,001$ & \multirow[t]{2}{*}{87898} \\
\hline RON & 196,9 & 24,3 & 244,6 & 65,50 & 1 & $<0,001$ & \\
\hline Intercept & $-80,5$ & 11,6 & $-57,67$ & 47,80 & 1 & $<0,001$ & \multirow[t]{2}{*}{86207} \\
\hline AON & 238,2 & 26,4 & 289,95 & 81,37 & 1 & $<0,001$ & \\
\hline
\end{tabular}

Figure 4 Table 2

\section{Discussion}

Experimental models of cerebral hematomas have been used since the 1960s. Initially, autologous blood was injected directly into the brain, a simple and effective technique for producing cerebral parenchymal hematoma. In larger animals such as dogs, cats, pigs and monkeys, the injection was performed in the frontal lobe (15-17). In smaller animals such as rats and mice, the site of choice was the caudate nucleus (18-25). These models allowed researchers to extrapolate the data obtained in animals to humans in a context closer to clinical practice than models that simulated trauma mechanisms. However, although the use of autologous blood allows the evaluation of biochemical effects of the blood on neurons, it does not provide a simple or direct way to evaluate the effects of hematoma evacuation surgery.

The use of an inflated balloon in the cerebral parenchyma (24) instead of blood (26) allowed us to simulate more uniform lesions, in addition to simulating the effect of surgical treatment with balloon emptying (27), although it does not include surgical access via craniotomy, corticectomy, hemostasis and the spreading effect of blood thru parenchyma, subarachnoid and ventricular spaces.

The choice of pigs for the animal models took into account the well-developed cortical and white matter structures more similar to the human brain compared to other animals, the possibility of using intracranial 
volumes 20 to 30 times greater compared to rodent models, the uniform state of health in pigs at this age, and the relatively low cost.

In our experimental model, we used a simulation of mass expansion, as may occur in cerebral hematomas when rebleeding, ventricular flooding or worsening of cerebral edema, with consequent elevation of ICP $(4+3 \mathrm{~mL}$ group). There are ongoing clinical trials focused on the reduction of controlled blood pressure in patients with cerebral hematomas that are seeking to avoid the expansion of hematomas and minimize the brain lesions induced by intracranial hypertension $(28,29)$. However, there are no studies analyzing the effects of hematoma expansion directly on intracranial pressure behavior. Even without grade 1 level of evidence, invasive ICP monitoring remains the standard recommendation for the management of patients with suspected ICHy (30). ONSD ultrasound would be a valuable adjunct to the gold-standard invasive technique.

Currently, a neurosurgical unit that receives requests for patient evaluations receives information that includes Glasgow Coma Scale values, vital signs, and possibly imaging tests. The ONSD ultrasound could dramatically change the way these cases are handled by discarding or confirming the ICHy diagnosis, allowing for better patient screening, and setting priorities with greater accuracy and safety. An estimate of the ICP value obtained from the bedside measurement of the optic nerve would support treatment providers in their decision making.

In addition, the cost of ONSD ultrasound is lower than that of other imaging methods used for the evaluation of ICP (computed tomography and nuclear magnetic resonance imaging). It can also be performed at the bedside without the transport of critical patients, and it involves a fast learning curve. Ballantyne et al. (31) studied ONSD ultrasound in healthy adults and observed that intra and inter-rater variability fell drastically after 17 measurements. Preliminary reports proposed that ONSD between $5.1 \mathrm{~mm}$ and $5.2 \mathrm{~mm}$ were associated with radiological signs of increased ICP in African and Asian patients with TBI. Specificity for most of these studies approached $100 \%$ with sensitivities ranging from $70 \%$ to $80 \%(32,33)$.

ONSD is especially important in low and middle-income country where disease as traumatic brain injury is epidemic and ICP monitoring usually is not available. One of the objectives of this study was to evaluate the ability of ONSD ultrasound to diagnose ICHy compared to the standard invasive monitoring of ICP.

An increased diameter of the optic nerve sheath can be compared with papilledema (optic disc edema). However, unlike papilledema, the expansion of the optic nerve sheath occurs seconds after an acute increase in ICP (34, 35).

ONSD ultrasound has been used to quantify variations in the optic nerve sheath and thus to detect elevations of ICP. Several authors have demonstrated a correlation between millimetric increases in the optic nerve sheath and ICHy (36-39). In 2012, Dubourg et al. (40) began a meta-analysis of studies comparing ONSD ultrasound and ICP catheter. The goal of the meta-analysis was to obtain an accurate ONSD ultrasound value for ICHy detection. They considered the clinical use of ONSD ultrasound only for screening purposes, never as a potential substitute for invasive ICP monitoring $(36,40-43)$. This is due to the fact that many of the models allowed only a qualitative and non-quantitative diagnosis of ICHy. Limiting factors of these models included the comparison of ONSD ultrasound with imaging tests (44) and lumbar puncture with manometry $(45,46)$. Even when compared to an ICP catheter, the selection of the sample for demographic characteristics, diagnosis, neurological status, and the impossibility of reproducing the same situations in a controlled environment were limiting factors in obtaining a quantitative prediction model of ICP using ONSD ultrasound. 
To date, the use of ONSD ultrasound is restricted to the average of the measurements obtained in each eye. No study has reported differences in the laterality of the ONSD measurements or in the localization of lesions with mass effect. The possibility of this correlation was studied by Strumwasser et al. (29), but a correlation was not found. In our experiments, AON was the best parameter for predicting ICP and presented the best correlation.

The hypothesis that there is a potential delay in changes in the optic nerve sheath compared to ICP has been observed also in our study, although it was about 30 minutes average after a comprehensive ICP reduction, which can occur in clinical practice with decompressive craniectomy or mass evacuation surgery. As in our study, the infusion of saline $3 \%$ solution did not reflect reduction either in ICP and ONSD values, we are not able to predict ONSD delays in case of small ICP reductions. However, the linear correlation indicates serial AON measures to be of value for ICP estimation and follow-up.

\section{Limitations}

This was an animal model to mimic ICHy, but in fact it does not comprise the critical pathogenic mechanisms and consequences of intracerebral hematoma $(\mathrm{ICH})$. ICH has been successfully modeled by autologous blood injection in pigs $(47,48)$, although our aim was to verify impact of progressive ICHy on ONSD.

Our study had no control group for comparison. We considered that the measures obtained at baseline, without $\mathrm{ICHy}$, characterized to a certain extent a control group, preventing the sacrifice of more animals for this single purpose, which, in addition to raising costs, would incur an ethical dilemma.

Only one examiner performed ONSD measurements. However, there are no other animal-model studies with more than one examiner. Even in humans, there is no recommendation for more than one examiner in clinical practice. Padayachy et al.(49) found a good correlation between 2 examiners (r: $0.89 p<0.001)$. Bäuerle et al.(50) found differences of less than $5 \%$ in the measurements obtained, also with a good correlation between 2 examiners ( $r>$ $0.82 \mathrm{p}<0.01$ ). Ballantyne et al. (2002) studied 67 patients with 3 examiners taking 3 measurements of each eye. The mean variability found among the examiners (+/- $0.2 \mathrm{~mm})$ was considered inherent to the device. In addition, after 17 measurements, intra- and inter-rater variability fell dramatically.

We observed no significant reduction in ICP with hypertonic saline infusion, thus, we were not able to estimate delay in ONSD reductions according to small ICP reductions, Also, we performed USG assessment immediately, 30 and 60 minutes after balloon deflation, with no precise estimation of ONSD delay to return to baseline levels, although results were significant at minute 30 .

Finally, the achievement of measures in a single transversal plane can also represent a limitation. Many studies $(32,36,40)$ used 2 planes of measurement for the optic, transverse, and sagittal nerve sheath, and the mean of the two is used for statistical analysis. In pigs, the sagittal plane is more difficult to measure due to the divergent strabismus of the animals under anesthesia. In our study, we tried to compensate for this limitation with 1 additional measurement to calculate the mean of each side (LON and RON).

\section{Conclusion}

In the present study, ultrasound of optic nerve sheath diameter disclosed linear correlation with ICP, although a short delay in returning to its baseline levels may be observed in the case of sudden intracranial hypertension 
relief.

\section{Declarations}

\section{Authors' contributions}

BCPJ, WSP, AFA, AB, MJ, MR, EBSS, MO, AMR, and DAG designed the paper. All authors participated in drafting and reviewing. All authors read and approved the final version of the manuscript.

\section{Competing interests and consent}

The authors declare no competing interest for this study and give consent for its publication.

\section{Consent for publication}

The authors revised this final version and give consent for its publication.

\section{Funding}

None.

\section{Availability of data and material}

Datasets used and/or analyzed during the current study are available from the corresponding author on reasonable request.

\section{Ethics approval}

The protocol was approved by the Research Ethical Committee at Sao Paulo University Medical School. The care and handling of the animals were in accord with the National Institutes of Health guidelines.

\section{Acknowledgements}

We thank Rogério Ruscitto do Prado, professional statist, for performing all statistical calculations.

\section{References}

1. Skoglund K, Enblad P, Marklund N. Monitoring and sedation differences in the management of severe head injury and subarachnoid hemorrhage among neurocritical care centers. J Neurosci Nurs. 2013;45(6):360-8.

2. de-Lima-Oliveira M, Ferreira AA, Belon AR, Salinet AM, Nogueira RC, Ping BC, et al. The influence of intracranial hypertension on static cerebral autoregulation. Brain Inj. 2020;34(9):1270-6.

3. Andrade AF, Soares MS, Patriota GC, Belon AR, Paiva WS, Bor-Seng-Shu E, et al. Experimental model of intracranial hypertension with continuous multiparametric monitoring in swine. Arq Neuropsiquiatr. 2013;71(10):802-6.

4. Paiva WS, de Andrade AF, Amorim RL, Figueiredo EG, Matushita $H$, Teixeira MJ. [Intracranial pressure monitoring in children with fulminant hepatic failure]. Rev Neurol. 2009;48(3):134-6. 
5. Badri S, Chen J, Barber J, Temkin NR, Dikmen SS, Chesnut RM, et al. Mortality and long-term functional outcome associated with intracranial pressure after traumatic brain injury. Intensive Care Med. 2012;38(11):1800-9.

6. Chesnut RM, Temkin N, Carney N, Dikmen S, Rondina C, Videtta W, et al. A trial of intracranial-pressure monitoring in traumatic brain injury. N Engl J Med. 2012;367(26):2471-81.

7. Chesnut RM, Petroni G, Rondina C. Intracranial-pressure monitoring in traumatic brain injury. N Engl J Med. 2013;368(18):1751-2.

8. Robba C, Pozzebon S, Moro B, Vincent JL, Creteur J, Taccone FS. Multimodal non-invasive assessment of intracranial hypertension: an observational study. Crit Care. 2020;24(1):379.

9. Rasulo FA, Bertuetti R, Robba C, Lusenti F, Cantoni A, Bernini M, et al. The accuracy of transcranial Doppler in excluding intracranial hypertension following acute brain injury: a multicenter prospective pilot study. Crit Care. 2017;21(1):44.

10. Tayal VS, Neulander M, Norton HJ, Foster T, Saunders T, Blaivas M. Emergency department sonographic measurement of optic nerve sheath diameter to detect findings of increased intracranial pressure in adult head injury patients. Ann Emerg Med. 2007;49(4):508-14.

11. Robba C, Santori G, Czosnyka M, Corradi F, Citerio G. Optic nerve sheath diameter: the next steps. Intensive Care Med. 2019.

12. Robba C, Santori G, Czosnyka M, Corradi F, Bragazzi N, Padayachy L, et al. Optic nerve sheath diameter measured sonographically as non-invasive estimator of intracranial pressure: a systematic review and metaanalysis. Intensive Care Med. 2018;44(8):1284-94.

13. Zhou J, Li J, Ye T, Zeng Y. Ultrasound measurements versus invasive intracranial pressure measurement method in patients with brain injury: a retrospective study. BMC Med Imaging. 2019;19(1):53.

14. Zeiler FA, Ziesmann MT, Goeres P, Unger B, Park J, Karakitsos D, et al. A unique method for estimating the reliability learning curve of optic nerve sheath diameter ultrasound measurement. Crit Ultrasound J. 2016;8(1):9.

15. Sussman BJ, Barber JB, Goald H. Experimental intracerebral hematoma. Reduction of oxygen tension in brain and cerebrospinal fluid. J Neurosurg. 1974;41(2):177-86.

16. Takasugi S, Ueda S, Matsumoto K. Chronological changes in spontaneous intracerebral hematoma-an experimental and clinical study. Stroke. 1985;16(4):651-8.

17. Wagner KR, Xi G, Hua Y, Kleinholz M, de Courten-Myers GM, Myers RE. Early metabolic alterations in edematous perihematomal brain regions following experimental intracerebral hemorrhage. J Neurosurg. 1998;88(6):1058-65.

18. Yang GY, Betz AL, Chenevert TL, Brunberg JA, Hoff JT. Experimental intracerebral hemorrhage: relationship between brain edema, blood flow, and blood-brain barrier permeability in rats. J Neurosurg. 1994;81(1):93102.

19. Xi G, Hua Y, Keep RF, Younger JG, Hoff JT. Systemic complement depletion diminishes perihematomal brain edema in rats. Stroke. 2001;32(1):162-7.

20. Hua Y, Xi G, Keep RF, Hoff JT. Complement activation in the brain after experimental intracerebral hemorrhage. J Neurosurg. 2000;92(6):1016-22. 
21. Belayev L, Saul I, Curbelo K, Busto R, Belayev A, Zhang Y, et al. Experimental intracerebral hemorrhage in the mouse: histological, behavioral, and hemodynamic characterization of a double-injection model. Stroke. 2003;34(9):2221-7.

22. Nakamura T, Xi G, Hua Y, Hoff JT, Keep RF. Nestin expression after experimental intracerebral hemorrhage. Brain Res. 2003;981(1-2):108-17.

23. Soldatos $T$, Chatzimichail K, Papathanasiou M, Gouliamos A. Optic nerve sonography: a new window for the non-invasive evaluation of intracranial pressure in brain injury. Emerg Med J. 2009;26(9):630-4.

24. Shi Y, Li Z, Zhang S, Xie M, Meng X, Xu J, et al. Establishing a model of supratentorial hemorrhage in the piglet. Tohoku J Exp Med. 2010;220(1):33-40.

25. Xi G, Wagner KR, Keep RF, Hua Y, de Courten-Myers GM, Broderick JP, et al. Role of blood clot formation on early edema development after experimental intracerebral hemorrhage. Stroke. 1998;29(12):2580-6.

26. de Lima Oliveira M, Salinet AM, Nogueira RC, Belon AR, Paiva WS, Jeng BCP, et al. The Effects of Induction and Treatment of Intracranial Hypertension on Cerebral Autoregulation: An Experimental Study. Neurol Res Int. 2018;2018:7053932.

27. Anderson RC, Kan P, Klimo P, Brockmeyer DL, Walker ML, Kestle JR. Complications of intracranial pressure monitoring in children with head trauma. J Neurosurg. 2004;101(1 Suppl):53-8.

28. Anderson JT, Wisner DH, Sullivan PE, Matteucci M, Freshman S, Hildreth J, et al. Initial small-volume hypertonic resuscitation of shock and brain injury: short- and long-term effects. J Trauma. 1997;42(4):592600. discussion -1 .

29. Strumwasser A, Kwan RO, Yeung L, Miraflor E, Ereso A, Castro-Moure F, et al. Sonographic optic nerve sheath diameter as an estimate of intracranial pressure in adult trauma. J Surg Res. 2011;170(2):265-71.

30. Levitt MR, Osbun JW, Kim LJ. Intracranial pressure monitoring in severe traumatic brain injury. World Neurosurg. 2013;79(5-6):600-1.

31. Ballantyne SA, O'Neill G, Hamilton R, Hollman AS. Observer variation in the sonographic measurement of optic nerve sheath diameter in normal adults. Eur J Ultrasound. 2002;15(3):145-9.

32. Chen LM, Wang LJ, Hu Y, Jiang XH, Wang YZ, Xing YQ. Ultrasonic measurement of optic nerve sheath diameter: a non-invasive surrogate approach for dynamic, real-time evaluation of intracranial pressure. $\mathrm{Br} \mathrm{J}$ Ophthalmol. 2019;103(4):437-41.

33. Aduayi OS, Asaleye CM, Adetiloye VA, Komolafe EO, Aduayi VA. Optic nerve sonography: A noninvasive means of detecting raised intracranial pressure in a resource-limited setting. J Neurosci Rural Pract. 2015;6(4):563-7.

34. Raboel PH, Bartek J Jr, Andresen M, Bellander BM, Romner B. Intracranial Pressure Monitoring: Invasive versus Non-Invasive Methods-A Review. Crit Care Res Pract. 2012;2012:950393.

35. Kristiansson H, Nissborg E, Bartek J Jr, Andresen M, Reinstrup P, Romner B. Reply to comment by Albin on "measuring elevated intracranial pressure through noninvasive methods: a review of the literature". J Neurosurg Anesthesiol. 2014;26(4):407.

36. Geeraerts T, Duranteau J, Benhamou D. Ocular sonography in patients with raised intracranial pressure: the papilloedema revisited. Crit Care. 2008;12(3):150.

37. Robba C, Cardim D, Czosnyka M, Abecasis F, Pezzato S, Buratti S, et al. Ultrasound non-invasive intracranial pressure assessment in paediatric neurocritical care: a pilot study. Childs Nerv Syst. 2020;36(1):117-24.

Page $11 / 15$ 
38. Rasulo FA, Bertuetti R. Transcranial Doppler and Optic Nerve Sonography. J Cardiothorac Vasc Anesth. 2019;33(Suppl 1):38-52.

39. Robba C, Cardim D, Tajsic T, Pietersen J, Bulman M, Rasulo F, et al. Non-invasive Intracranial Pressure Assessment in Brain Injured Patients Using Ultrasound-Based Methods. Acta Neurochir Suppl. 2018;126:6973.

40. Dubourg J, Messerer M, Karakitsos D, Rajajee V, Antonsen E, Javouhey E, et al. Individual patient data systematic review and meta-analysis of optic nerve sheath diameter ultrasonography for detecting raised intracranial pressure: protocol of the ONSD research group. Syst Rev. 2013;2:62.

41. Kimberly HH, Shah S, Marill K, Noble V. Correlation of optic nerve sheath diameter with direct measurement of intracranial pressure. Acad Emerg Med. 2008;15(2):201-4.

42. Kim H, Yu T, Cam-Etoz B, van Groen T, Hubbard WJ, Chaudry IH. Treatment of traumatic brain injury with 17alpha-ethinylestradiol-3-sulfate in a rat model. J Neurosurg. 2017;127(1):23-31.

43. Dubourg J, Javouhey E, Geeraerts T, Messerer M, Kassai B. Ultrasonography of optic nerve sheath diameter for detection of raised intracranial pressure: a systematic review and meta-analysis. Intensive Care Med. 2011;37(7):1059-68.

44. Komut E, Kozaci N, Sonmez BM, Yilmaz F, Komut S, Yildirim ZN, et al. Bedside sonographic measurement of optic nerve sheath diameter as a predictor of intracranial pressure in ED. Am J Emerg Med. 2016;34(6):9637.

45. Amini A, Eghtesadi R, Feizi AM, Mansouri B, Kariman H, Dolatabadi AA, et al. Sonographic Optic Nerve Sheath Diameter as a Screening Tool for Detection of Elevated Intracranial Pressure. Emerg (Tehran). 2013;1(1):159.

46. Wang L, Feng L, Yao Y, Wang Y, Chen Y, Feng J, et al. Optimal optic nerve sheath diameter threshold for the identification of elevated opening pressure on lumbar puncture in a Chinese population. PLoS One. 2015;10(2):e0117939.

47. Sindelar B, Bailes J, Sherman S, Finan J, Stone J, Lee J, et al. Effect of Internal Jugular Vein Compression on Intracranial Hemorrhage in a Porcine Controlled Cortical Impact Model. J Neurotrauma. 2017;34(8):1703-9.

48. Rise IR, Risoe C, Kirkeby OJ. Cerebrovascular effects of high intracranial pressure after moderate hemorrhage. J Neurosurg Anesthesiol. 1998;10(4):224-30.

49. Padayachy LC, Padayachy V, Galal U, Gray R, Fieggen AG. The relationship between transorbital ultrasound measurement of the optic nerve sheath diameter (ONSD) and invasively measured ICP in children: Part I: repeatability, observer variability and general analysis. Childs Nerv Syst. 2016;32(10):1769-78.

50. Bauerle J, Schuchardt F, Schroeder L, Egger K, Weigel M, Harloff A. Reproducibility and accuracy of optic nerve sheath diameter assessment using ultrasound compared to magnetic resonance imaging. BMC Neurol. 2013;13:187.

\section{Figures}




\section{9 brash, $18,6 \mathrm{~m}$}

$20148 \mathrm{Set} 02$

-

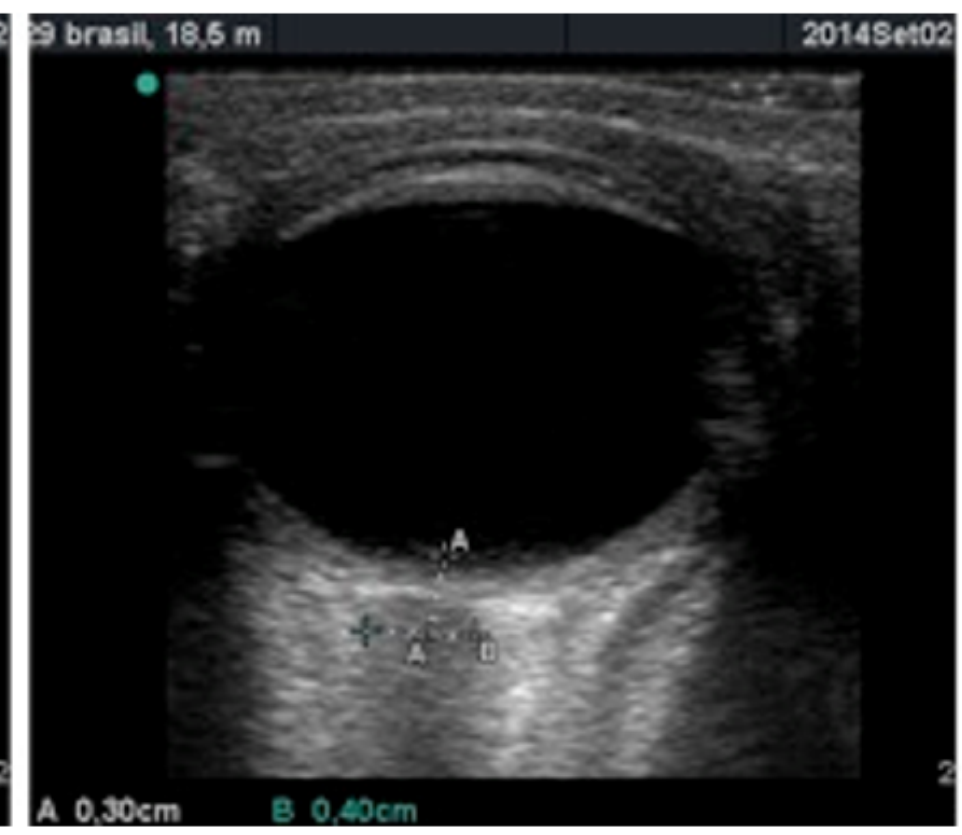

\section{Figure 1}

Optic nerve insonation and sheath measure technique of left and right eyes; 3 millimeters depth from de optic disc (A) and a transversal line drawn at this point (B).

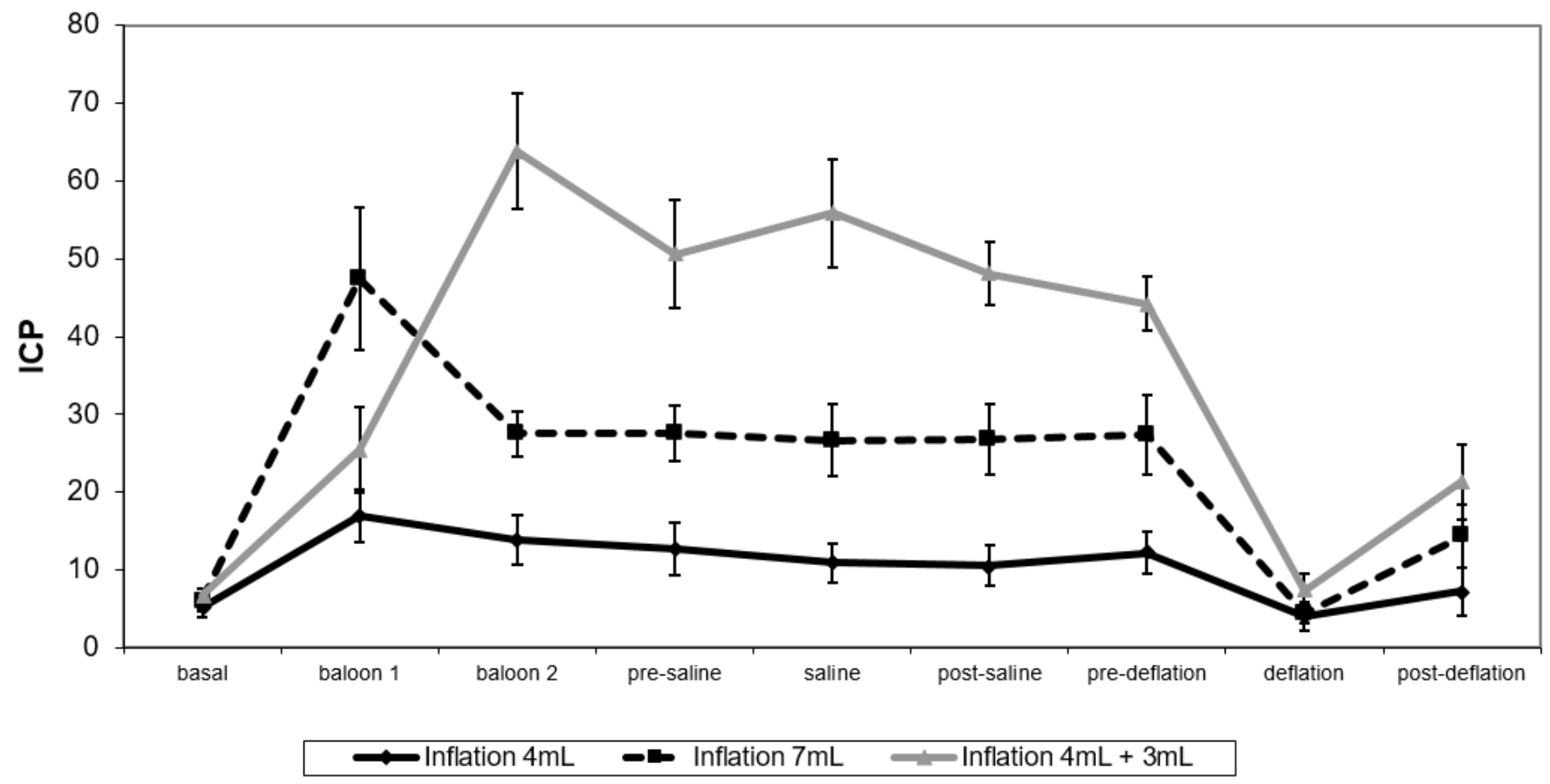

Figure 2

Mean values and respective ICP standard errors according to groups and interventions. 


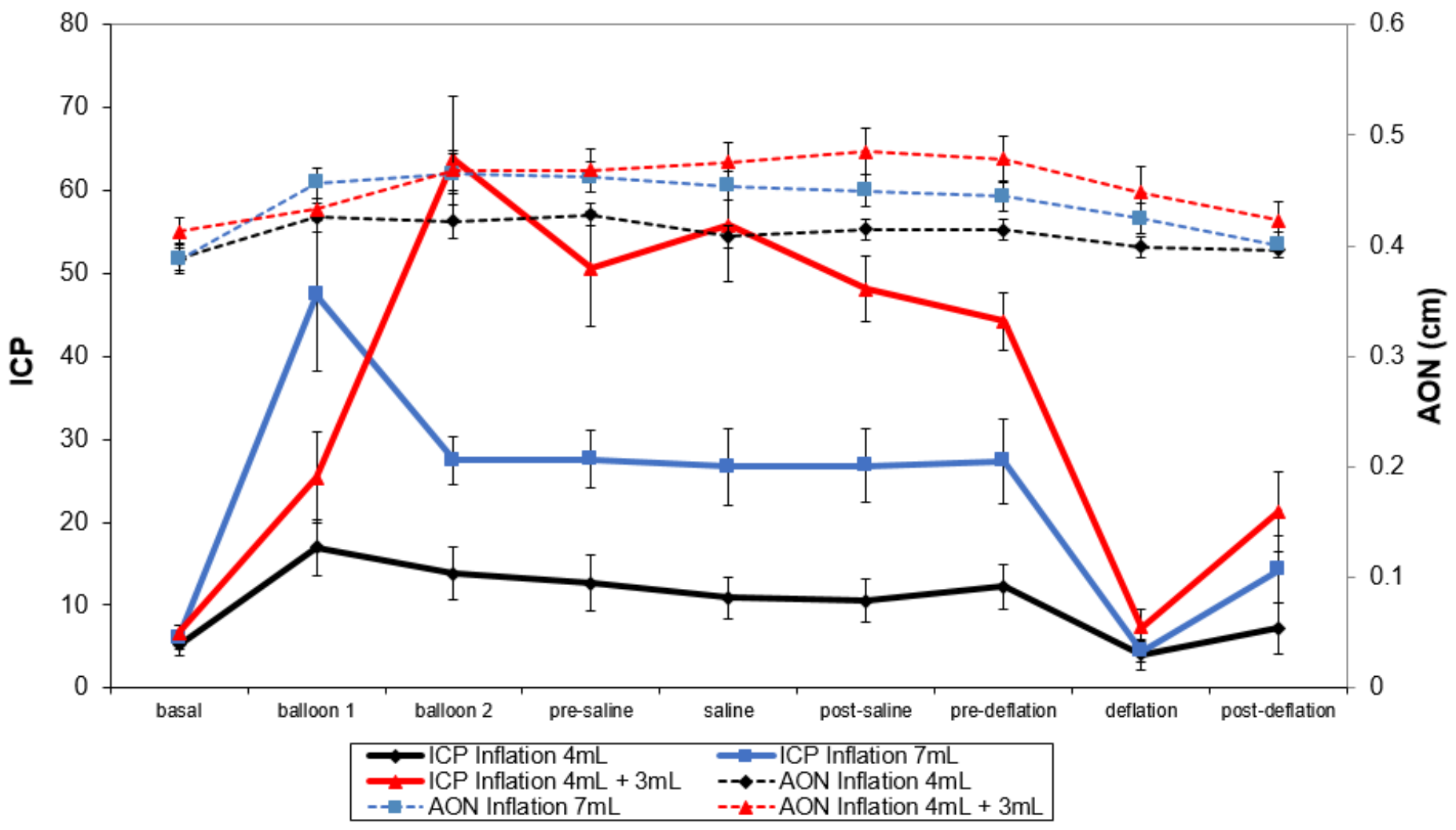

Figure 3

Interventions and time-lapse ICP and AON trends. AON remained significantly higher than baseline during the entire procedure for $7 \mathrm{~mL}$ and $4+3 \mathrm{~mL}$ groups, until balloon deflation.

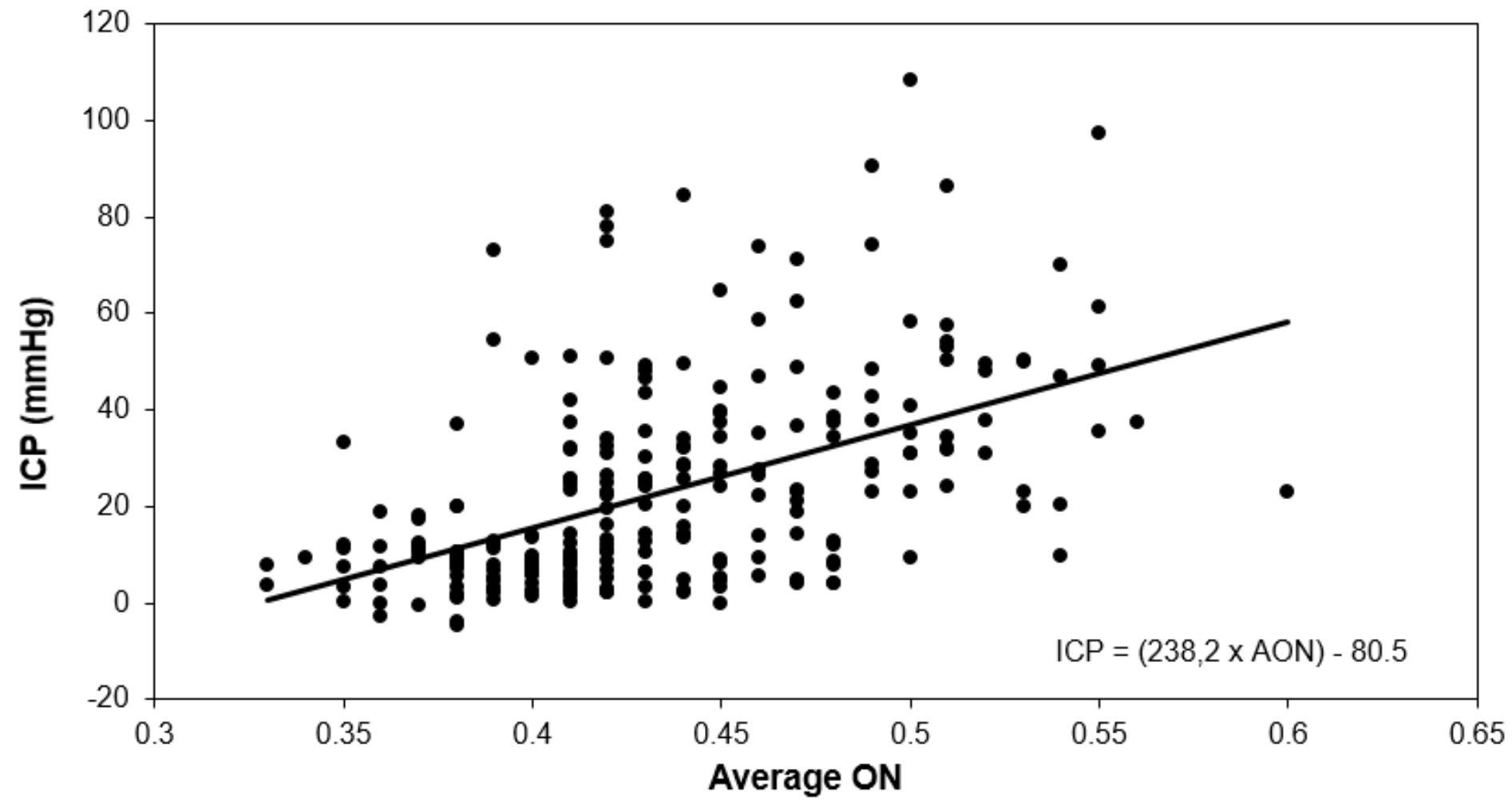

Figure 4 
ICP dispersion diagram (standard error) as a function of average $\mathrm{ON}$ and trend line. 